\title{
Anatomy of human mitral valve in adult cadaver and comparative anatomy of the valve
}

\author{
ROBERT WALMSLEY
}

From The Department of Anatomy and Experimental Pathology, The University, St Andrews, Scotland

SUMMARY A comparative anatomical study of the mitral ring and the 2 major mitral cusps of 12 adult mammals, including man, has been made. Two $25 \mathrm{~mm}$ thick sections of 2 adult human thoraces were cut to show the position and orientation of the adult mitral valve as it lies in the chest of the cadaver. Thin sections of hearts and valves were prepared so that the structure and basal attachments of the cusps could be examined microscopically.

In most human hearts there is no distinctive, well-defined fibrous thickening or ring at the basal attachment of the aortic (anterior) mitral cusp: the mitral 'ring' is therefore considered to be usually incomplete anteriorly. This is consistent with the findings in the hearts of all other mammals examined. The posterior part of the ring is interposed between the myocardium of left atrium and left ventricle and corresponds to the region of the attachment of the mural (posterior) cusp of the mitral valve. In most mammals, including man, this part of the ring is a well-defined band of collagen: in a few mammals, including the sheep, the ring is represented by a thin lamina of loose collagen. The relation of the free wall of the left ventricle to the posterior part of the ring is of functional significance as it is the ventricular myocardium that is responsible for the major changes in the circumference of the ring occurring posteriorly during the cardiac cycle. In the ruminant ungulates, the sheep and ox, the aortic (anterior) mitral cusp has an attachment that is common to it and the related cusps of the aortic valve.

Each cusp has two zones whose structure is an expression of their function. There is in each cusp a distal 'appositional' zone whose substance is formed of a loose meshwork of collagen fibres. In the fresh heart it is soft to touch and comes into apposition with a corresponding zone on the opposing cusp during closure of the valve. The proximal part of the cusp is called the 'free' zone which does not come into contact with the opposing cusp. The characteristic feature of the free zone is the presence of a stratum of denser collagen, the lamina fibrosa. The denseness of the collagen in the lamina varies considerably in different animals. In some mammals, including man, there is usually a ridge of demarcation between the appositional and free zones: this, when present, represents the 'line of closure' of the valve. The amount of left atrial muscle in the mitral valve cusps varies considerably in different mammals.

Because of the great variation in the structure, attachments, relative size, and mobility of the 2 major mitral cusps in different animals, it is considered that there are basic differences in the mitral valves of different mammals.

With the introduction of echocardiography it appears to be apposite to reinvestigate the anatomy of the mitral valve. The mitral valve is customarily described as a complex consisting of a fibrous ring or annulus, two major cusps, chordae tendineae, and two major papillary muscles (Silverman and Hurst, 1968). The indentations between the cusps do not, however, reach the fibrous ring because the basal parts of the cusps are joined by commissural areas

Received for publication 18 April 1977 or leaflets. Adjacent to the valve ring there is, therefore, a cuff of valvular tissue, all of which is concerned with the function of the mitral valve.

In order to appreciate fully the structure of the mitral complex in the human heart it has been of considerable value to examine the valve in other mammals: by adopting this comparative anatomical approach the full significance of some features of the human valve cusps becomes more apparent. This study is concerned mainly with the attachments, structure, and form of the two major cusps in 12 
mammals, including man. The two major cusps are called aortic (anterior) and mural (posterior) and these terms are equally applicable to man in the erect position and to quadruped mammals. Frater and Ellis (1961) claim, in a study of the canine valve, that there is no basic difference in the anatomy of the mitral valve in the dog from that in several other mammals examined by them, including man. As much experimental work has been done on different animals, an additional purpose of this work is to analyse this important assumption and attempt to verify its validity.

Many previous observations on the mitral valve have been made after it had been resected by a circumferential incision on the atrial and ventricular sides of the mitral ring and the cusps removed either along with the chordae and papillary muscles or without them. This method has been adopted in the important work of Chiechi et al. (1956), Du Plessis and Marchand (1964), Ellison and Hibbs (1973), and others. The procedure adopted in this study has been to prepare microscopical sections of the mitral valve either as it lies in situ in the entire heart or, as in larger mammals, to prepare sections of the full lengths of the aortic and mural cusps.

\section{Subjects and methods}

The hearts of the 12 adult mammals examined were those of man, horse, ox, sheep, pig, dog, rabbit, cat, guinea-pig, hedgehog, opossum, and rat. At least 3 hearts of each animal have been examined and more than 30 human hearts were used. The hearts were obtained as soon as possible after death and fixed by the injection of 12 per cent neutral formalin into the coronary arteries. Sections of the entire human heart and of the hearts of all animals smaller than the sheep were prepared to show both the inflow and outflow tracts of the left ventricle and also the wall of the right ventricle. In order to obtain such sections an initial cut was made through the heart, passing as nearly as possible through the middle of the mitral valve and also through the ascending aorta in line with the right and left coronary cusps. An attempt was always made to cut through the greatest length of the aortic cusp of the valve. In larger hearts the opposing parts of the aortic and mural cusps were resected. The blocks containing the aortic cusp were removed along with the adjacent parts of the left atrium and the ascending aorta, whereas the blocks with the mural cusp contained the adjacent left atrial and ventricular walls and the intervening fibrous ring. Sections of the entire heart and blocks containing the separate cusps were cut at thicknesses that varied between 8 and
$15 \mu$ and stained with Masson trichrome and orcein elastic tissue stains.

The approach adopted in this comparative study of the mitral valve is to describe the principal features of the human valve and thereafter describe and illustrate the major differences in attachment and structure of the two major cusps in other animals. The hearts of quadruped mammals standing on four legs, it will be understood, lie at an angle of $90^{\circ}$ to the heart of man as he stands in the erect position. The terminology adopted is applicable, as far as possible, to both the upright and quadruped body positions.

\section{Results}

\section{MAN}

It cannot be stressed sufficiently that the atrial and ventricular septa lie at an angle of approximately $45^{\circ}$ to the median plane so that the right heart lies as much in front of the left heart as it does to its right side (Fig. 1). The two atrioventricular orifices are directed forwards and to the left and the blood in passing from the posteriorly placed atria into the ventricles is thus directed forwards and to the left parallel to the ventricular septum. In this part of its course the blood has little, if any, downwards inclination.

In order to view the two atrioventricular orifices from the atrial side a $25 \mathrm{~mm}$ thick oblique vertical section of an entire human adult thorax was made so that the posterior cut passed through the atria, a little behind the basal attachments of the cusps of the two atrioventricular valves to their fibrous rings (Fig. 2). The plane in which the thorax was cut is indicated by an interrupted line in Fig. 1. Fig. 2 shows that the cut of the section has passed directly behind the fibrous mitral ring but a part of the lateral wall of the right atrium lies behind the lateral part of the tricuspid fibrous ring: this is because the mitral and tricuspid rings do not, certainly in this specimen, lie precisely in the same oblique vertical plane. The alignment of the two atrioventricular rings is influenced principally by the degree of dilatation of the right atrium: in Fig. 1 the right atrium is dilated and this is the usual condition in the hearts of cadavers. The orifice of the mitral valve is orientated vertically, is irregular in contour and the commissural areas lie one above the other: the commissures, therefore, should be designated 'superior' and 'inferior' (or 'upper' and 'lower'). This is certainly the orientation of the mitral orifice in all human cadavers examined but it may well be that in the living heart the orientation changes considerably during the cardiac cycle. Fig. 3 is an oblique section of the heart from another human cadaver, passing 


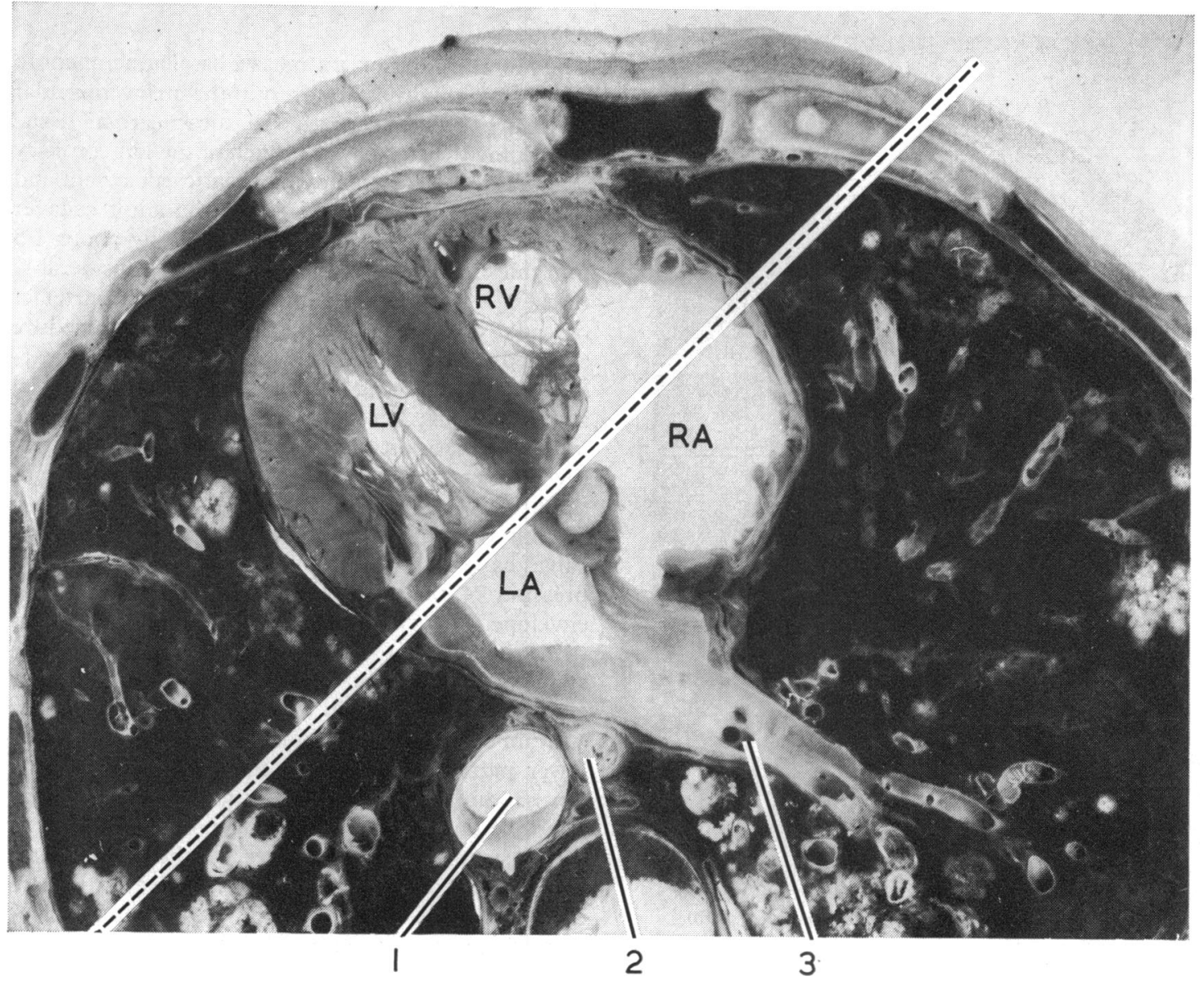

Fig. 1 Part of the transverse section of the adult human thorax at the level of the fourth costal cartilages. The two chambers of the right heart (RA and $R V$ ) are seen to lie as much in front of the two left heart chambers (LA and LV) as they lie to their right side. The interrupted line shows the plane of the posterior cut of the vertical section shown in Fig. 2. The line passes immediately behind the fibrous ring of the mitral valve but on the right side passes through the lateral wall of the dilated right atrium behind the atrioventricular sulcus. A small part of the right wall of the ascending aorta lies immediately behind the interrupted line adjacent to the atrial septum. (I) Descending aorta; (2) oesophagus; (3) right lower pulmonary vein.

through the entire left heart, the proximal part of the ascending aorta, the ventricular septum, and the right ventricle. The illustration has been orientated so that the left atrium lies behind the left ventricle, as it does, but on account of the oblique cut of the heart, the lower free wall of the ventricle is the true posterolateral (or pulmonary) wall of the chamber.

\section{Intervalvar septum and fibrous mitral ring}

The attachment of the anterior wall of the left atrium to the region of the base of the aortic cusp of the mitral valve lies below the left coronary cusp of the aortic valve. The interval between the semilunar cusp of the aortic valve and the basal attachment of the mitral aortic cusp is bridged by a membranous septum which is here called the intervalvar septum. This septum has been called the intervalvular space by others and will be considered in the Discussion. In adult hearts the septum varies in length between 2 and $10 \mathrm{~mm}$. At its upper end the septum is always attached to the fibrous ring of the aortic valve (Fig. 4, 5a, and 5b) and its lower end is usually continuous with the lamina fibrosa of the aortic cusp of the mitral valve (Fig. 4 and 5a). Sometimes, but only rarely, a fibrous ring of the mitral valve is present in this region (Fig. 5b), which gives attachment to the lamina fibrosa of the aortic cusp of the mitral valve. When a mitral ring is present at this site it is separated from the intervalvar septum by a gap no more than $2 \mathrm{~mm}$ wide. 


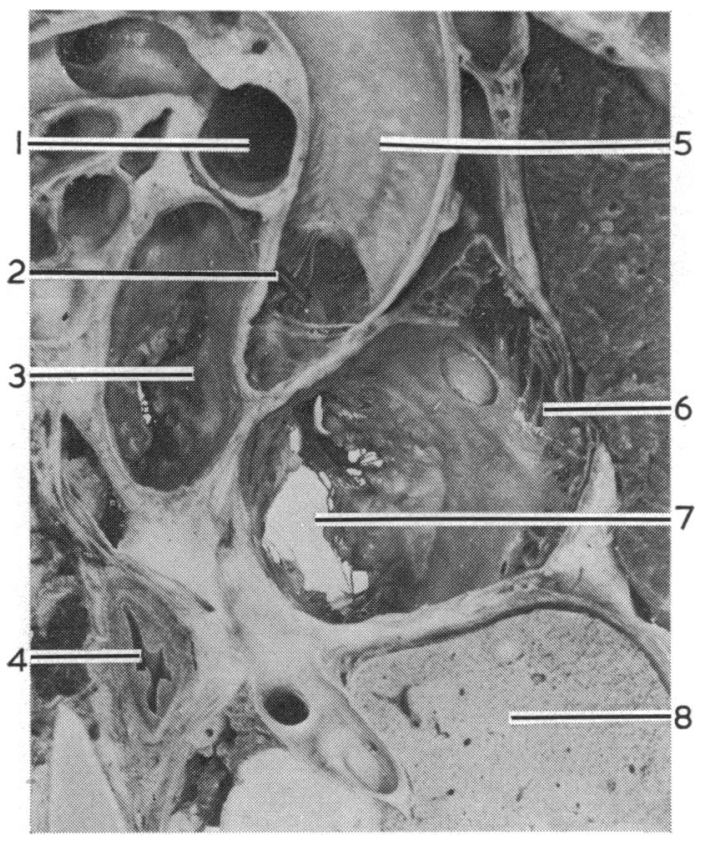

Fig. 2 Part of the posterior surface of an oblique vertical section of an adult human thorax cut in the plane indicated by the interrupted line in Fig. 1. The cut has passed immediately behind the mitral fibrous ring but on the right side passed through the lateral wall of the right atrium. The close relation of the aortic (anterior) cusp of the mitral valve to the left coronary and noncoronary cusps of the aortic valve is apparent. Glass rods indicate the orifices of the left and right coronary arteries. The orifice of the mitral valve is irregular in contour and in the cadaver is orientated vertically.

(1) Right pulmonary artery; (2) left coronary artery; (3) aortic (anterior) cusp of mitral valve; (4) oesophagus; (5) ascending aorta; (6) lateral wall of right atrium;

(7) tricuspid orifice; (8) liver.

The usual absence of a thickening of fibrous tissue at the base of the aortic cusp of the mitral valve has been observed by several workers and is considered in the Discussion. The myocardial fibres of the roof of the left atrium are attached to the intervalvar septum at its junction with the mitral aortic cusp: when a fibrous mitral ring is present some of these muscle fibres are attached to the septum, some to the ring, and some are continued downwards for a variable distance in the subendocardial tissue of the atrial aspect of the mitral aortic cusp. When there is no definite fibrous mitral ring, as in Fig. 4 and 5a, the indefinitely defined and non-thickened fibrous zone adjacent to the attachment of the atrial fibres into the lower end of the intervalvar septum might be regarded as representing the mitral ring.
Mitral cusps

The mural (posterior) cusp has a basal attachment to the fibrous ring that lies deep in the atrioventricular (coronary) sulcus beneath the subepicardial tissue containing the circumflex branch of the left coronary artery and the accompanying great cardiac vein and its tributaries (Fig. 3 and 4 ). In the adult cadaver heart this segment of the ring is usually about 1.5 $\mathrm{mm}$ thick; in the living heart it may be considerably thicker, as a diminution in size may be an artefact caused by changes after death and the procedure adopted in the preparation of sections. In a 71-yearold woman the ring was $4 \mathrm{~mm}$ thick. The basal attachment of the cusp extends along the entire length of that part of the fibrous ring which lies in the atrioventricular sulcus on the external surface of the heart.

Both the aortic and mural cusps of the mitral valve have two parts whose structure is an expression of their function. Both mitral cusps are enveloped in endocardium which is continuous with the endocardium of the chordae tendineae attached to the cusps. The basal or proximal part of a cusp is relatively thin and is formed mainly by a stratum of collagen, the lamina fibrosa. The distal or lower part of each cusp is thicker, has no lamina fibrosa, and comes into apposition with that of the opposing cusp during the closure of the valve. It is well recognised that the area of the valve cusps greatly exceeds that of the valve orifice: it is here considered that, in part at least, this is the result of there being a specific appositional zone in each major cusp. It is on account of this surface-to-surface contact of the distal parts of the cusps that an effective seal of the valve orifice is ensured during closure of the valve. The distal part of a cusp is, therefore, called the 'appositional' zone and the basal part is called the 'free' zone.

\section{Aortic cusp}

The basal attachment of the supporting lamina fibrosa of the free zone of this cusp has already been described. The lamina is reinforced by chordae tendineae of the second order which are inserted into the ventricular surface of the cusp. At its lower end the lamina usually ends abruptly (Fig. $5 \mathrm{a}$ ) but rarely it becomes attenuated and blends with the loose collagen of the appositional zone (Fig. 5b). The atrial layer of the endocardium is thicker than the ventricular layer and the atrial subendocardium contains a variable amount of left atrial myocardium.

The substance of the thicker appositional zone is formed mainly by a loose meshwork of interlacing collagen fibres embedded in a semifluid ground substance and its surface is smoother on its atrial than its ventricular surface: it lacks a lamina fibrosa 


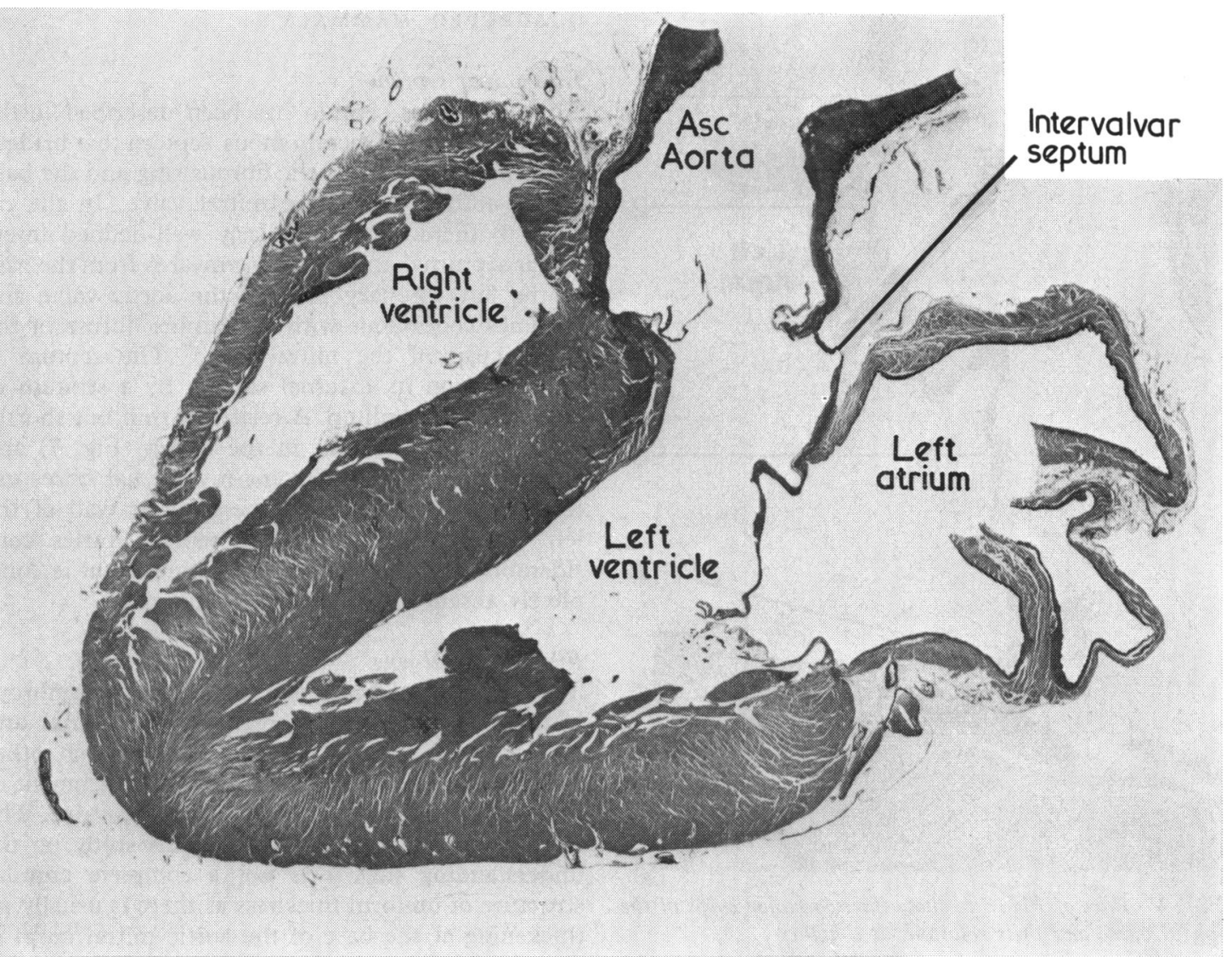

Fig. 3 Oblique section of the heart of a 50-year-old man. The section has passed through the entire left heart, the proximal part of the ascending aorta, the ventricular septum, and the right ventricle. Between the left coronary aortic cusp and the base of the aortic (anterior) cusp of the mitral valve there is the intervalvar septum. This is the longest septum seen in the human hearts that have been examined. $(\times 1 \cdot 5$.

(Fig. 5a). Numerous fine chordae tendineae of the first order gain attachment to its free edge, and prevent it being everted into the atrial cavity during ventricular systole. There is no zone in any cusp in any animal that shows a greater variation in size and structure than the appositional zone of the human mitral aortic cusp, and extremes are shown in Fig. $5 \mathrm{a}$ and $5 \mathrm{~b}$.

The mitral aortic cusp in the human heart is a large cusp (Fig. 4), has a semicircular or triangular form, and the relative lengths of its free and appositional zones vary along its breadth. The line of demarcation between the free and appositional zones may be very apparent to the naked eye when the whole cusp is inspected, as in Fig. 5a, and is then called the 'line of closure' of the cusp. In a few mitral aortic cusps, however, this sharp line of demarcation between the two cusp zones is absént
(Fig. 5b) and the free zone is then considered to be that part of the cusp that contains a well-defined lamina fibrosa. The appositional zone in such cusps gradually merges into the free zone and the fact that this may occur is of functional significance: this is the normal pattern of the mitral aortic cusp in the dog (see Fig. 9). In the intermediate part of the cusp the free zone is longer than the appositional zone (Fig. 5a).

\section{Mural cusp}

This cusp is rectangular in form, has a basal attachment that is wider than that of the aortic cusp, but its length, which is about $12 \mathrm{~mm}$, is little more than half the length of the aortic cusp: its free border usually has two or more indentations. The line of demarcation between the free and appositional zones is always clearly demarcated and it is readily 


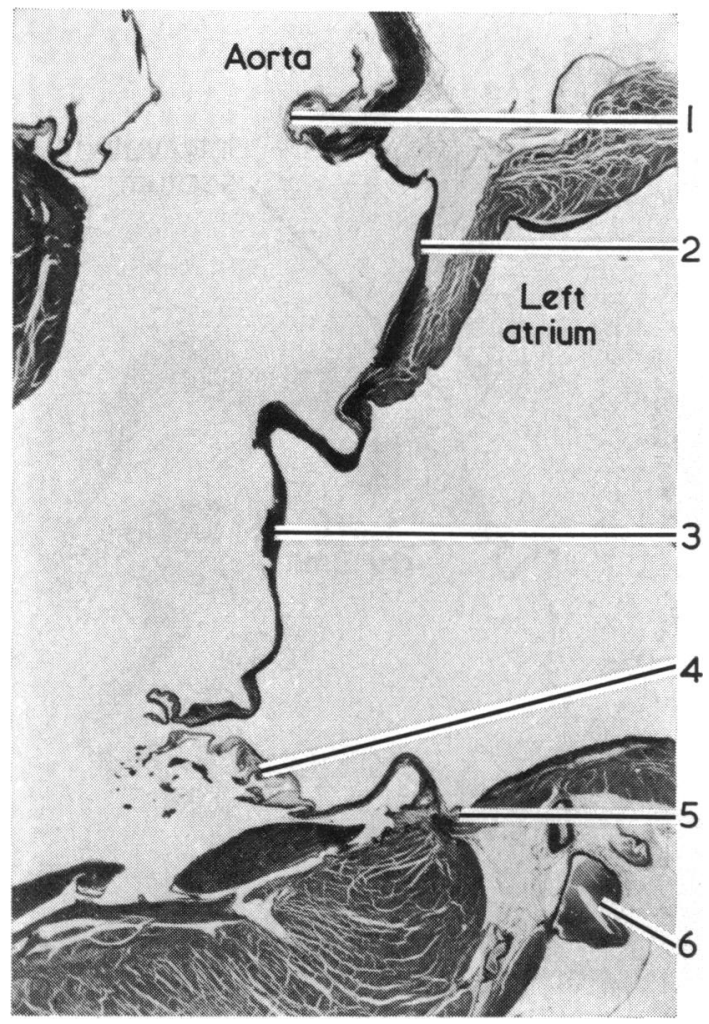

Fig. 4 Part of Fig. 3 to show the two major cusps of the mitral valve and their relations at a higher magnification. The line of junction between the appositional and free zones of the mural (posterior) cusp is clearly demarcated. The circumflex branch of the left coronary artery and the great cardiac vein lie in the subepicardial tissue overlying the fibrous ring. At the basal attachment of the aortic (anterior) cusp the mitral fibrous ring is absent and the lamina fibrosa of this cusp is continuous with the intervalvar septum. ( $\times 3$.) (1) Left coronary cusp of aortic valve; (2) intervalvar septum; (3) aortic cusp of mitral valve; (4) mural cusp appositional zone; (5) mitral fibrous ring; (6) circumflex branch of left coronary artery.

apparent that the lamina fibrosa is restricted to the free zone (Fig. 4). The lamina fibrosa is in part attached to the fibrous ring and in part it blends with the subendocardium of the left ventricle. This relation of the lamina fibrosa to the subendocardium overlying the left ventricular myocardium is considered to be of functional significance.

The appositional zone of the mural cusp is approximately the same length as its free zone and is considerably thicker than it (Fig. 4); in this tigure the loose texture of the substance of this zone is also seen.

\section{QUADRUPED MAMMALS}

\section{Intervalvar septum}

The intervalvar septum has been described in the human heart as a membranous septum that bridges the gap between the aortic fibrous ring and the base of the aortic cusp of the mitral valve. In the rat (Fig. 6) there is a particularly well-defined intervalvar septum that extends downwards from the base of the left coronary cusp of the aortic valve and becomes continuous with the lamina fibrosa of the aortic cusp of the mitral valve. The septum is reinforced on its external surface by a stratum of left atrial myocardium. A relatively thin but shorter septum is also present in the rabbit (Fig. 7) and overlying it are the adjacent myocardial fibres extending downwards from the anterior wall of the left atrium. The intervalvar septum varies considerably in length in different animals but is completely absent in the sheep and the ox.

\section{Fibrous mitral ring}

The term mitral 'ring' is a misnomer. The fibrous 'ring' is limited to the region where atrial and ventricular myocardia are adjacent to each other and this corresponds to the region of attachment of the mural (posterior) cusp of the mitral valve. The term 'ring' is, however, used in this study on the understanding that it is not a complete annular structure of uniform thickness as there is usually no thickening at the base of the aortic mitral cusp. A segment of the ring, at the base of the mural cusp, is very obvious in the rabbit (Fig. 7), and is also always present in the human heart (Fig. 4). In the guinea-pig (Fig. 14) the ring is apparent and its close relation to the mass of muscle of the left ventricle is of major functional significance. The distinctness of the ring in the region of the mural cusp would, certainly at first sight, appear to vary in different breeds of the same animal. In a section of the entire heart of a mongrel dog (Fig. 8) the ring is apparent, but in a section of the heart of an Alsatian dog (Fig. 9) the ring is not visible to the naked eye. Nevertheless, on microscopical examination a distinct lamina of fibrous tissue is seen to intervene between atrial and ventricular myocardia. In the sheep, the mitral ring is even more inconspicuous (Fig. 10), but here again the atrial and ventricular myocardia are seen microscopically to be separated by a fibrous lamina. Sections of a part of the sheep's heart were prepared after removal of a block of tissue containing the adjacent parts of the walls of the left atrium, left ventricle, and the mural cusp of the mitral valve. In such sections the mitral ring is represented by a thin lamina of loose collagen separating the muscular walls of atria and ventricles. In the 


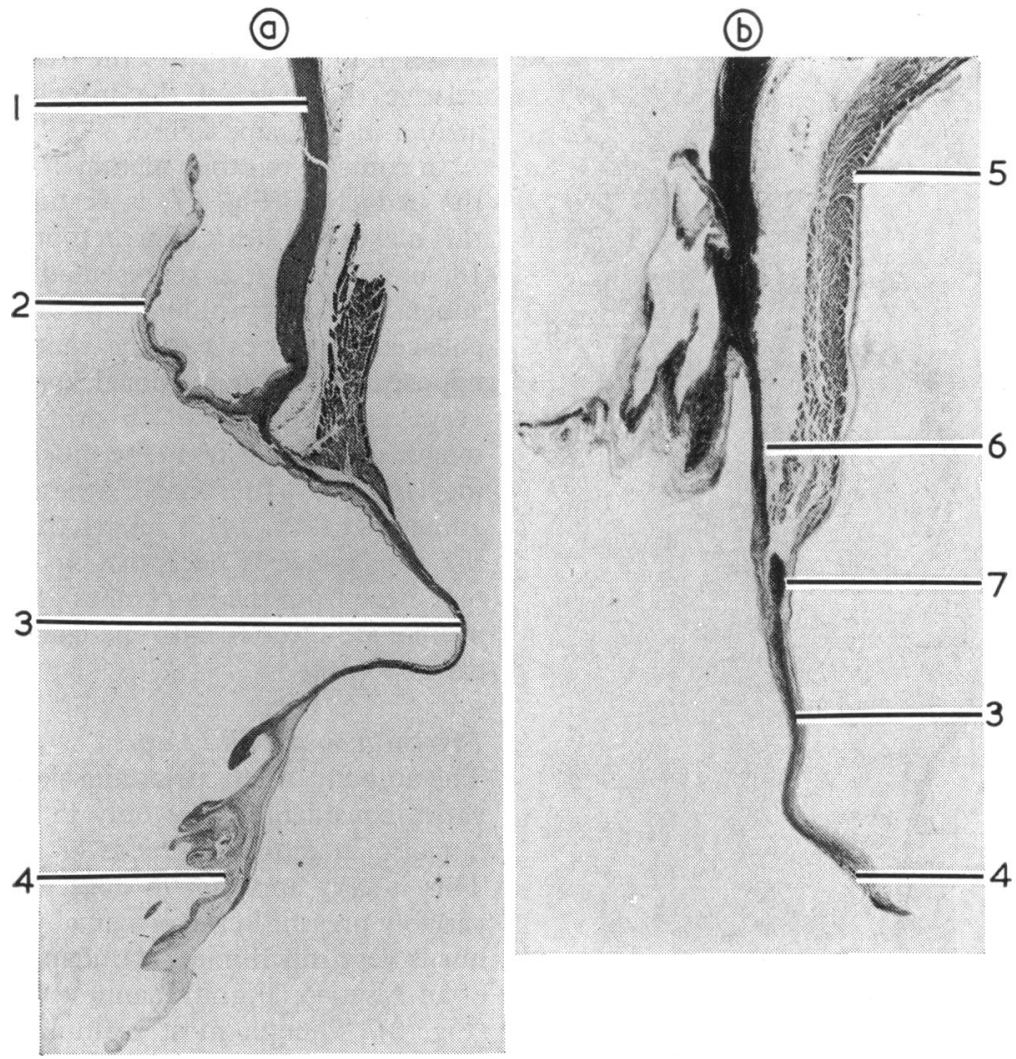

Fig. 5 (a) Typical human aortic mitral cusp with well-demarcated free and appositional zones. No mitral fibrous ring is present and the lamina fibrosa of the cusp is attached to the aortic valve fibrous ring through the intervalvar septum. (b) Unusual form of human aortic mitral cusp. Mitral ring is present and is separated from the intervalvar septum by a small gap. The appositional zone has an unusual form and there is no sharp line of demarcation between it and the free zone of the cusp. Section is near the junction of the left coronary and non-coronary cusps of the aortic valve. $(\times 3).(1)$ Wall of aorta; (2) left coronary cusp of aortic valve; (3) free zone; (4) appositional zone; (5) left atrial myocardium; (6) intervalvar septum; (7) mitral ring.

hedgehog (Fig. 12 and 13), where the mural cusp is vestigial, the thin-walled atrium is attached to a narrow but dense fibrous band that lies on the upper (or dorsal) surface of the free wall of the thick left ventricle.

\section{Mitral cusps}

As has already been stated, the aortic (anterior) and mural (posterior) cusps usually have two zones, a proximal free zone and a distal appositional zone. The free zones of the two cusps do not come into apposition with each other but separate atrial from ventricular blood while the valve is closed. The free zone is characterised by a lamina fibrosa that varies considerably in character in different mammals.

In the aortic cusp in many mammals such as the rabbit (Fig. 7), dog (Fig. 8 and 9) and hedgehog (Fig. 12) the lamina fibrosa is flexible and is formed of collagen fibres orientated longitudinally with flattened fibrocytes lying between them (Fig. 15). In the sheep (Fig. 10) on the other hand, the lamina is extremely dense and is firm on palpation: in another ruminant ungulate, the ox (Fig. 11), the free zone is relatively non-resilient. In the sheep, ox, and hedgehog, the lamina fibrosa is attached proximally to a ring that is common to it and the aortic valve cusps: in the ox this ring is formed of calcified cartilage. In other mammals the proximal attach- 


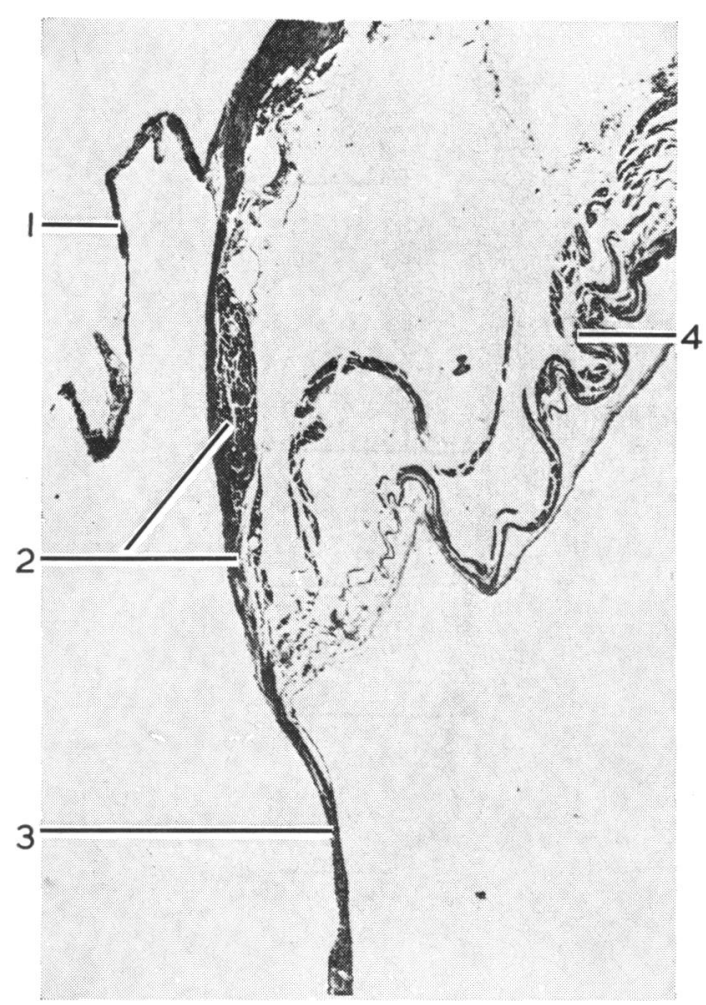

Fig. 6 Microphotograph of intervalvar septum of a rat. The septum is continuous with the lamina fibrosa of the aortic cusp of mitral valve. At its upper end the septum blends with the ill-defined aortic valve fibrous ring. There is no mitral fibrous ring. $(\times 50$.) (1) Left coronary cusp of aortic valve; (2) intervalvar septum and overlying myocardium; (3) free zone aortic mitral cusp; (4) left atrial myocardium.

ment of the lamina fibrosa is essentially as in the typical human heart where no definite fibrous thickening is present at the base of the cusp.

The appositional zones of the aortic cusps of the mitral valve always lack a lamina fibrosa and their substance is formed of a loose meshwork of collagen fibres. In some animals, particularly the sheep (Fig. 10) and the ox (Fig. 11), the appositional and free zones are sharply demarcated from each other. In other animals such as the dog (Fig. 9) the line of demarcation between the zones is not obvious on surface examination.

The mural cusp varies considerably in different mammals. In some animals, such as the sheep (Fig. 10) and ox, the cusp is entirely appositional in type. In these animals the loose collagen of the cusp is directly continuous with the subendocardium of the left atrium. The fact that the mural cusp appears longer than the aortic cusp in the sheep in Fig. 10 is an artefact resulting from the obliquity of the plane of section: this is also the reason for the great relative thickness of the inferior wall of the left atrium in the same figure.

In contrast to other mammals the mural cusp in the hedgehog (Fig. 12) is vestigial and immobile: this makes it a heart of great morphological interest. In some places it is represented by no more than a subendocardial proliferation of moderately loose collagen on the part of the ventricular wall that is opposed to the appositional zone of the relatively very long aortic cusp. In other places there is a tongue of tissue distal to the subendocardial thickening (Fig. 13). In contrast, the mural cusp in the guinea-pig (Fig. 14) is longer than the aortic cusp; the appearance is deceptive in Fig. 14 as chordae tendineae from the two bellies of the same papillary muscle are inserted into the corresponding parts of the two cusps.

\section{Myocardium in valve cusps}

The amount of left atrial muscle in the valve cusps varies considerably not only in different mammals but also in different breeds of the same mammal. This is very apparent in dogs where muscle is invariably present in the proximal parts of both cusps, but is very much more abundant in the aortic cusp of an Alsatian (Fig. 9) than in that of a mongrel dog (Fig. 8). Though most mammals have a variable amount of muscle in the subendocardium of the mitral aortic cusp, in the rabbit (Fig. 7) the atrial myocardium sweeps into the free zone of the mural cusp but terminates at the base of the aortic cusp.

\section{Discussion}

Sections prepared to show the structure and attachments of the two major cusps of the mitral valve do not give a complete picture of all features of the valve complex. They yield no information about the commissural regions nor do they indicate the ratio of the surface area of the cusps to that of the valve orifice. Furthermore, the observations are made on the preserved hearts of cadavers, and the amount of constriction of the valve orifice that occurs during ventricular systole cannot be measured. The relative sizes of mitral cusp area and orifice area has, however, received considerable attention since Creutzfeldt's (1897) description. The finding of Chiechi et al. (1956) that the proportion of the cusp area to the orifice area in the human heart is never less than 1.5 to 1 and may be as great as 2 to 1 is in general agreement with the measurements of most other workers.

The entire section of the thorax from which Fig. 1 is taken has been published by Walmsley (1958), 


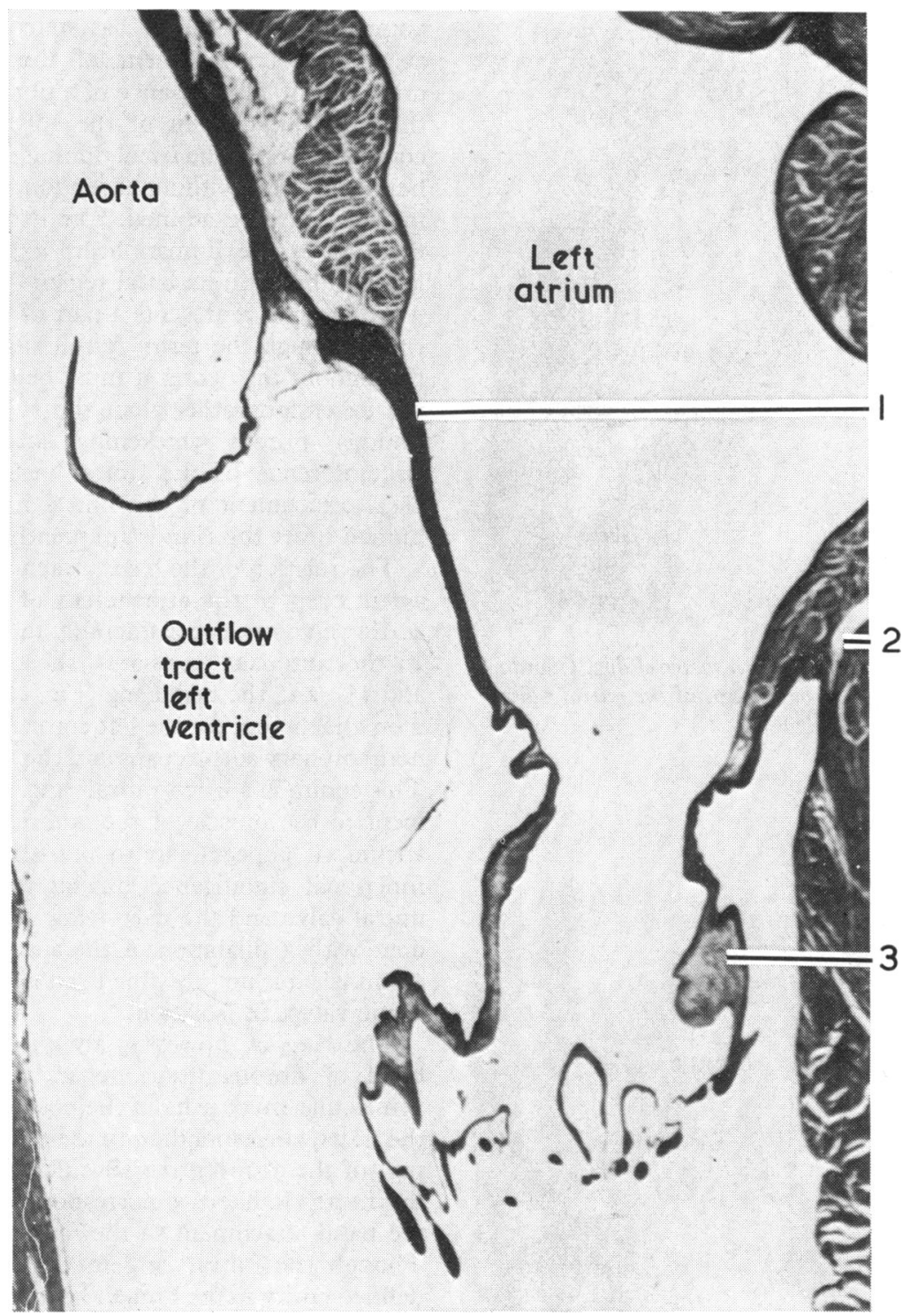

Fig. 7 Mitral valve of a rabbit. Though the lamina fibrosa of the mitral aor tic cusp thickens in its upper part there is no definite mitral fibrous ring. Caudally, a segment of the mitral fibrous ring is interposed between the atrial and ventricular myocardia. There is a short but thin intervalvar septum below the base of the left coronary cusp of the aortic valve. The form of the free and appositional zones of both cusps is apparent and left atrial fibres extend into the mural cusp. ( $\times 15$.) (I) Aortic cusp, free zone; (2) mitral ring; (3) mural cusp, appositional zone.

Walmsley and Watson (1966), and Walmsley and Watson (1978). It shows in the cadaver the relation of the mitral valve to other cardiac structures and the way the heart is orientated in the thorax. Drawings of the heart in situ, as opposed to photographs, have been published by Silverman and Hurst (1968) and Sahn et al. (1975) but give a misleading impression of the manner in which the heart lies in the chest.

Since Chiechi et al. (1956) reported that the mitral ring in the human heart is incomplete 


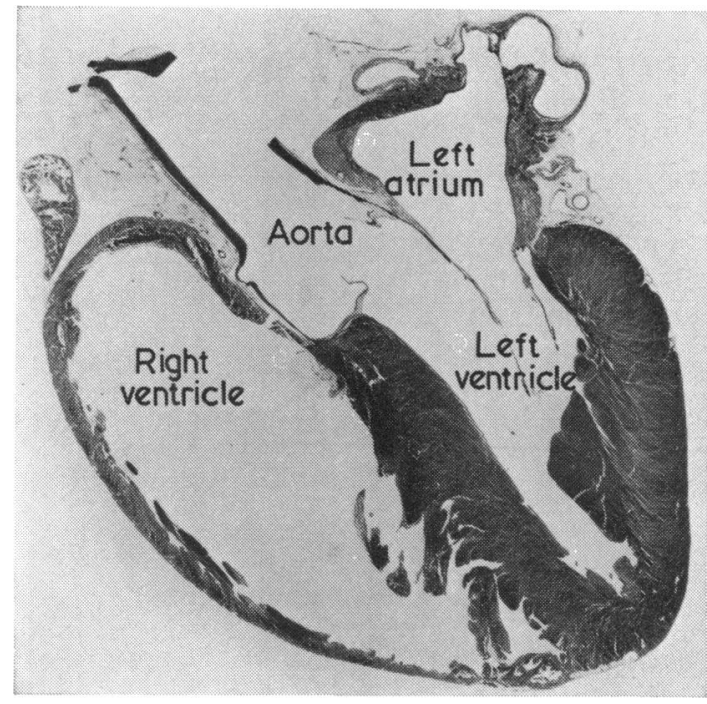

Fig. 8 Section of the heart of a mongrel dog. Chordae tendineae are attached to both cusps of the mitral valve which make them appear long. $(\times 1$.

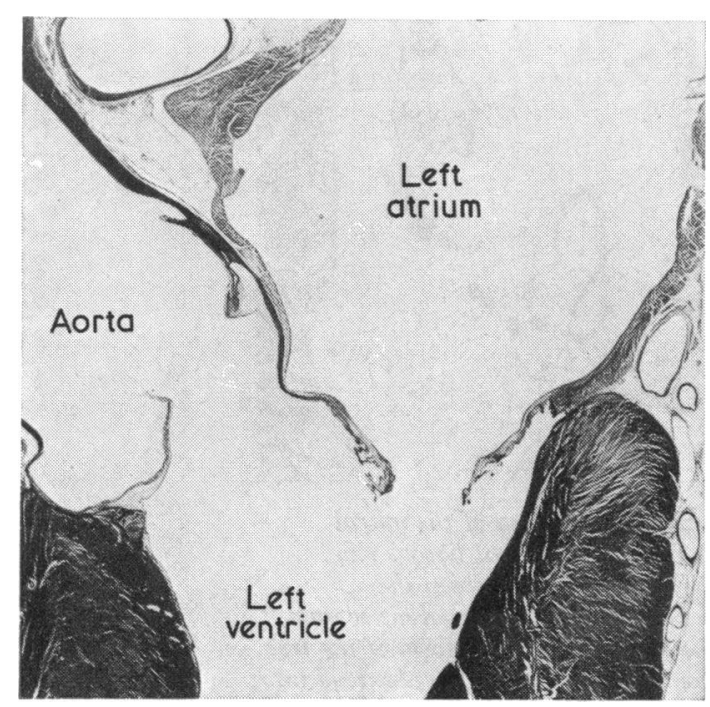

Fig. 9 Mitral valve of Alsatian dog. The section has passed through the aorta at the junction of the left coronary and non-coronary cusps of the aortic valve. In the dog's heart the appositional zones of the mitral cusps do not show the usual thickness of this zone. In the aortic cusp the lamina fibrosa (dark line) is limited to the basal two-thirds of the cusp: proximally it is attached to the fibrous ring of aortic valve. Left atrial muscle extends into the basal half of aortic cusp. $(\times 3$. anteriorly, Loop (1975) has stated that it is absent at the basal attachment of the aortic (anterior) mitral cusp. This absence of a fibrous thickening at the basal attachment of the aortic cusp has been confirmed and is the usual finding not only in human hearts but also, without exception, in all other mammalian hearts examined. On occasions, however, there is in the human heart a thickening of the lamina fibrosa in its basal region (Fig. 5b) and this, when present, represents a part of the mitral fibrous ring. Though the term 'mitral ring' has been used throughout this work, it must be accepted that it is the exception rather than the rule to find a continuous fibrous thickening around the entire circumference of the mitral orifice. Even at the basal attachment of the mitral mural cusp in the human heart the ring is frequently narrow (Fig. 4).

The relation of the basal attachment of the mitral aortic cusp to the attachment of the cusps of the aortic valve varies considerably in different animals. In the ruminant ungulates, sheep and ox (Fig. 10 and 11), and the hedgehog (Fig. 12) there is a common attachment for the left coronary and part of the non-coronary aortic cusps and the mitral aortic cusp. This common aortico-mitral ring also gives attachment to the muscle of the anterior wall of the left atrium: it appears fair to postulate that this is of functional significance during the closure of the mitral valve and the narrowing of its orifice coincident with a dilatation of the aortic orifice. In such mammals it is not possible to consider the mitral and aortic valves in isolation.

The ring is, however, always represented by a band of fibrous tissue separating the atrial and ventricular myocardia in the posterolateral region of the heart, corresponding to the region of the deepest part of the atrioventricular sulcus on the surface of the heart. It likewise corresponds to the region of the basal attachment of the mural (posterior) cusp. Though the mitral ring in this region is a welldefined entity in the human heart (Fig. 4), the rabbit (Fig. 7), and the guinea-pig (Fig. 14), it is not an obvious entity in all mammals. In the sheep (Fig. 10), for example, the posterolateral part of the ring is apparent only on microscopical examination of this region of the heart where it is represented by a thin stratum of loose collagen.

It is generally accepted that the diameter of the mitral orifice is reduced considerably during ventricular systole and this has been ascribed to the deep circular fibres of the left ventricle (Chiechi et al., 1956). All observations made in this comparative anatomical study have shown that the ventricular muscle is limited to the region of the mitral ring that gives attachment to the mural cusp of the mitral valve: this is very obvious in the human 


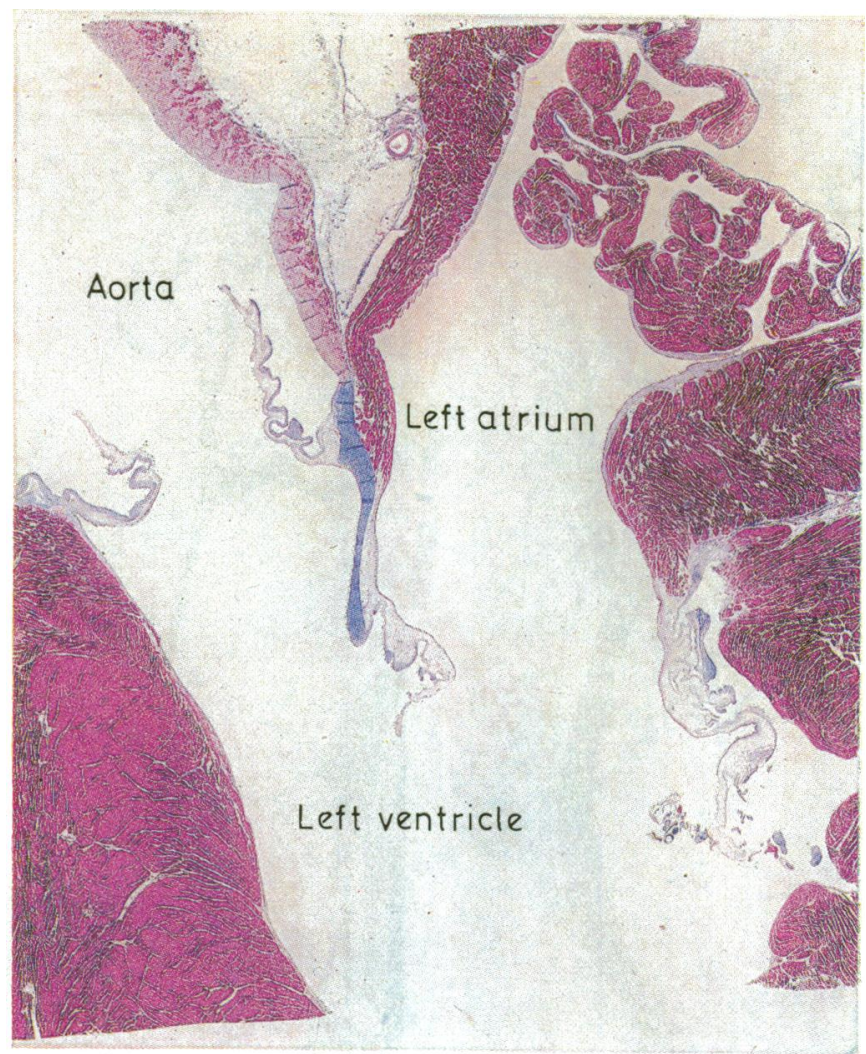

Fig. 10 Mitral valve of sheep. The myocardial floor of the left atrium is thick and microscopically a lamina of fibrous tissue is seen to separate it from the myocardium of the left ventricle. The mural cusp appears long owing to obliquity of the section and is entirely appositional in type. There is a dense plate of collagen representing the lamina fibrosa in the upper three-fifths of the aortic cusp. The upper end of the lamina is attached to a ring that is common to it and the cusp of the aortic valve. The distal two-fifths of the aortic cusp are typical of an appositional zone. $(\times 3$.)

heart in Fig. 3 and 4. It cannot be sufficiently emphasised that the ventricular myocardium does not completely encircle the mitral orifice but is restricted to its posterolateral region. It is for this very reason that the major changes in the circumference of the mitral ring during the cardiac cycle occur in the posterolateral region.

The manner in which the mitral aortic cusp in the human heart separates the inflow tract from the upper part of the outflow of the left ventricle (the aortic vestibule, subaortic, or subvalvar region) has been described by Walmsley and Watson (1966). The intimate relation of the mitral aortic cusp to the two blood flow pathways of the left heart is apparent in the human heart (Fig. 3), dog's heart (Fig. 8), and the guinea-pig's heart (Fig. 14): like- wise in every mammalian heart examined the relation is the same.

In the sheep, ox, and hedgehog there is a common aortico-mitral ring that affords attachment to cusps of the two left heart valves, whereas in other mammals the relation of the two valves to each other is less intimate. In these animals the attachments of the relevant cusps of the two valves are separated by a membranous septum, the intervalvar septum. This septum has an upper attachment to the bases of the cusps of the aortic valve and below it is usually continuous with the lamina fibrosa of the mitral aortic cusp. The intervalvar septum is very apparent in the rat (Fig. 6) and is also usually present in the human heart (Fig. 4 and 5b) and in the hearts of some other animals such as the rabbit (Fig. 7). This 


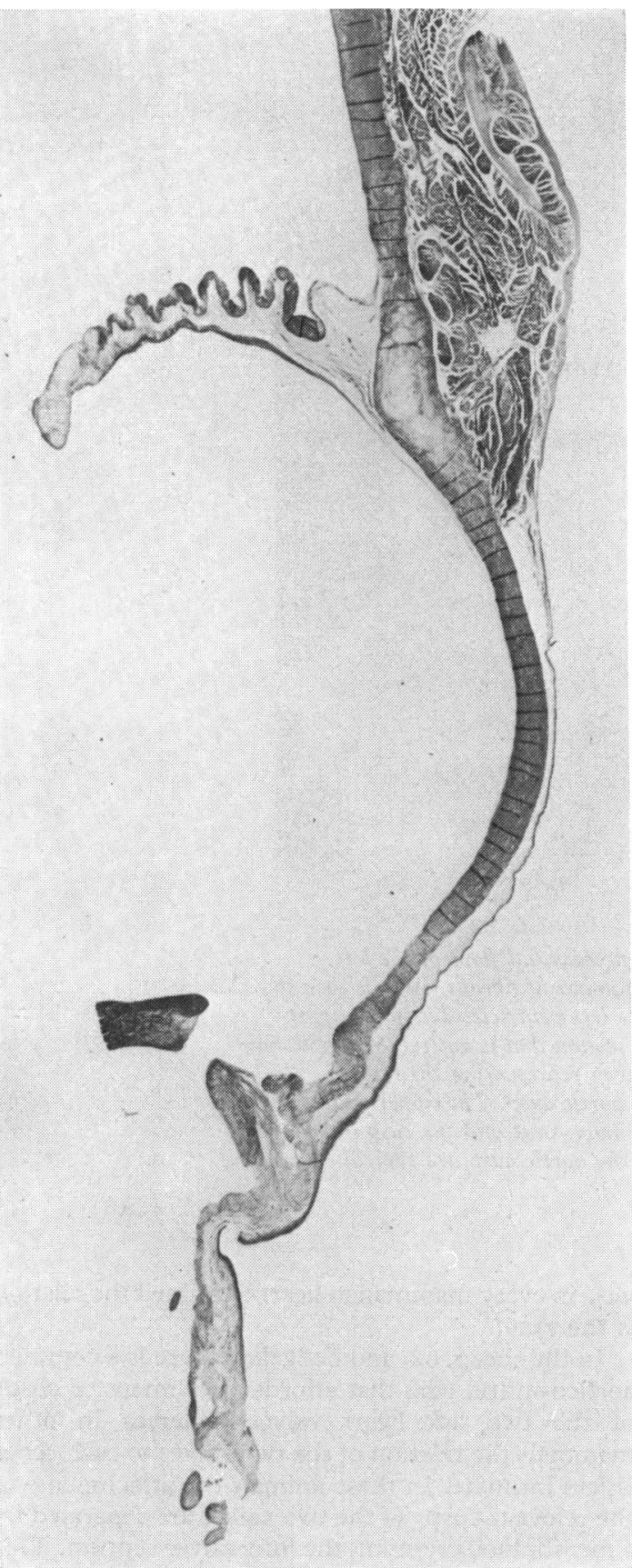

Fig. 11 The aortic cusp of the mitral valve of an ox. The upper two-thirds of the cusp contains a dense lamina fibrosa that is attached at its upper end to a calcified cartilage ring that is common to it and the left coronary cusp of the aortic valve. The distal third of the cusp is typical of an appositional zonc. $(\times 3.5$.)

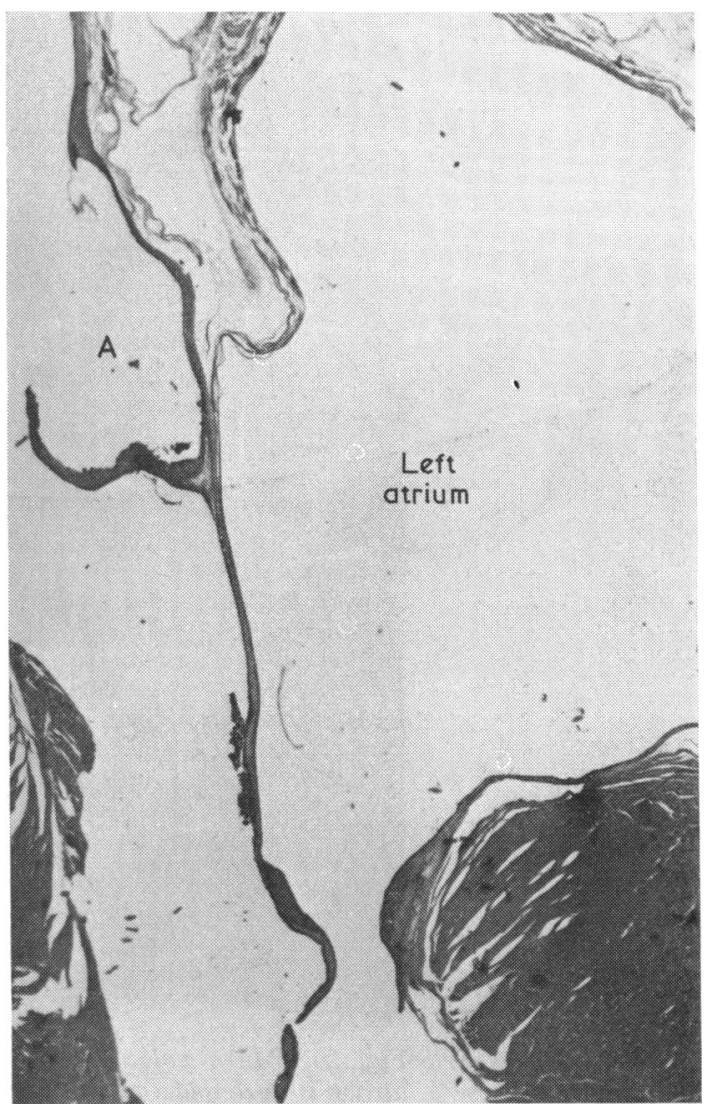

Fig. 12 Mitral valve of a hedgehog. This mitral valve is characterised by an extremely long aortic cusp and an immobile mural cusp. At its upper end the lamina fibrosa of the aortic cusp bifurcates, one layer being continuous with the wall of the aortic sinus $(A)$ and the other with the cusp of the aortic valve. This long aortic cusp separates the inflow from the outflow tract of the left ventricle. The mural cusp is vestigial and is adherent to the endocardium of the left ventricle. $(\times 15$.

septum has been recognised by Du Plessis and Marchand (1964) who have called it the intervalvular 'space'. A septum of collagen cannot, however, constitute a 'space'. Valvula is the name frequently given to a semilunar cusp of the aortic or pulmonary valves. The term 'intervalvular space' was used by $T$. Walmsley (1929) to describe the triangular interval between two aortic or pulmonary cusps when viewed from the arterial side but not to the actual septum itself: it is a part of the septum that constitutes the floor of the space. The intervalvar septum shows considerable variation in length in human hearts but in any single heart it is always longest near the junction of the left coronary and 


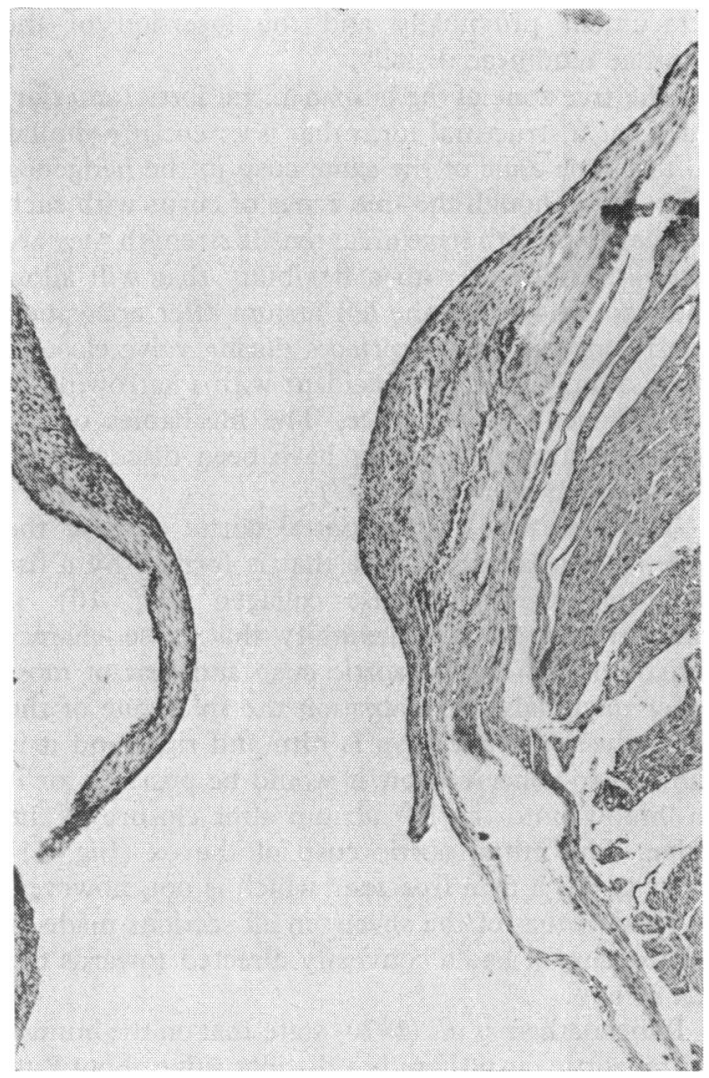

Fig. 13 Appositional zones of the mitral aortic cusp and vestigial immobile mural cusp of the hedgehog. The appositional zone of the aortic cusp is formed of much looser collagen than the free zone (Fig. 15). The apparently free tongue representing the mural cusp is fused in much of its length with the ventricular endocardium. $(\times 180$.

the non-coronary aortic cusps: so too, the septum is shortest at the lowest point of attachment of either of these two semilunar cusps.

The principal purpose to this work is to show that each major cusp of the mitral valve has two distinct zones and that the structure of each zone is an expression of its function. The zones are named the appositional zone and the free zone. Both cusps have a covering of endocardium which can be described as the atrial and ventricular layers: at the free edge of the cusp the layers are continuous with each other and are also continued on to the chordae tendineae.

The appositional zone is the part of a cusp that meets a corresponding zone on the opposing cusp during the closure of the valve. Its substance, within the endocardium, consists of a loose meshwork of

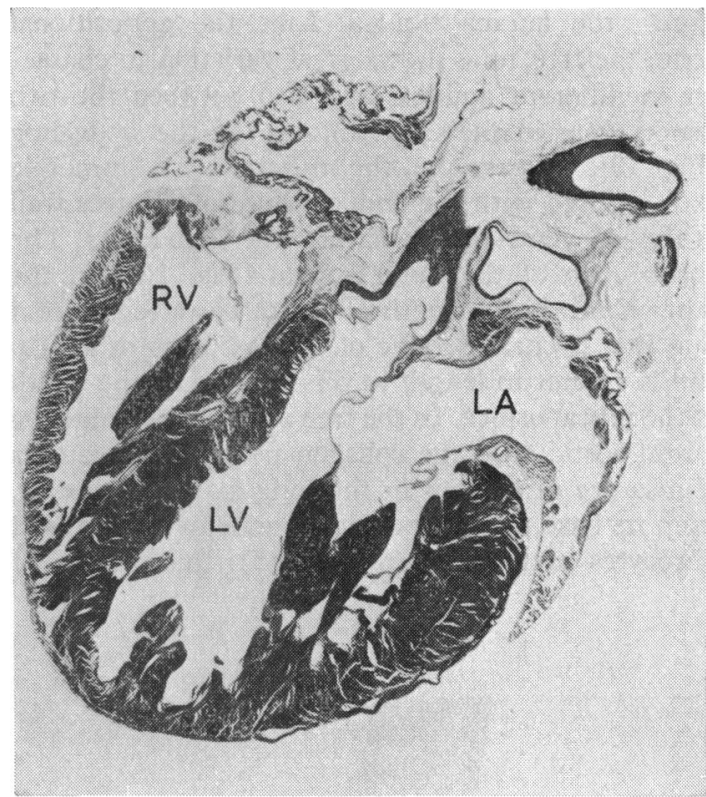

Fig. 14 Section of the heart of a guinea-pig. The papillary muscle in the left ventricle $(L V)$ has two bellies and from them chordae tendineae pass to the corresponding parts of the aortic and mural cusps of the mitral valve. In the guinea-pig the mural cusp is longer than the aortic cusp but this is not readily apparent because of the attachment of the chordae to the free edges of the cusps. $(\times 4$.

interlacing collagen fibres and a few elastic fibres embedded in a semifluid ground substance. Within the ground substance are a variable number of fibrocytes. It does not possess a lamina fibrosa. The appositional zone is usually thicker than the free zone, but even if it is not thicker, as in the dog (Fig. 9), it is soft to touch. This softness allows the opposing appositional zones of the two cusps to adapt themselves to each other, surface to surface, during closure of the valve, so that a water-tight seal is created. It is a matter of interest that in a detailed study of the canine mitral valve Fenoglio et al. (1972) named the distal part of each cusp the zona spongiosa.

The free zone of a cusp is the non-appositional part that lies proximal to the appostional zone: during closure of the valve the two free zones of the cusps separate atrial from ventricular blood. Brock (1952) used the term 'free' area to indicate the part of the mural cusp that is not in contact with its fellow cusp during closure of the human mitral valve.

The characteristic feature of the substance of the free zone is the presence of a stratum of collagen 
fibres, the lamina fibrosa. Like the appositional zone, the free zone shows great variation in character in different animals and also between the two major cusps in the same animal. In the hedgehog (Fig. 13), for example, the mural cusp is immobile as it is fused with the endocardium of the free wall of the left ventricle, so that no free zone exists. The aortic cusp of the same animal (Fig. 12), on the other hand, in its length of $5 \mathrm{~mm}$ has a region of 4 $\mathrm{mm}$ that is characteristic of the free zone of a cusp and is greater in length in this heart than the width of the mitral orifice. In the free zone of the hedgehog mitral aortic cusp the collagen fibres of the lamina fibrosa are orientated in the long axis of the cusp, from its base to its appositional zone, with flattened fibrocytes between them (Fig. 15): this pattern of

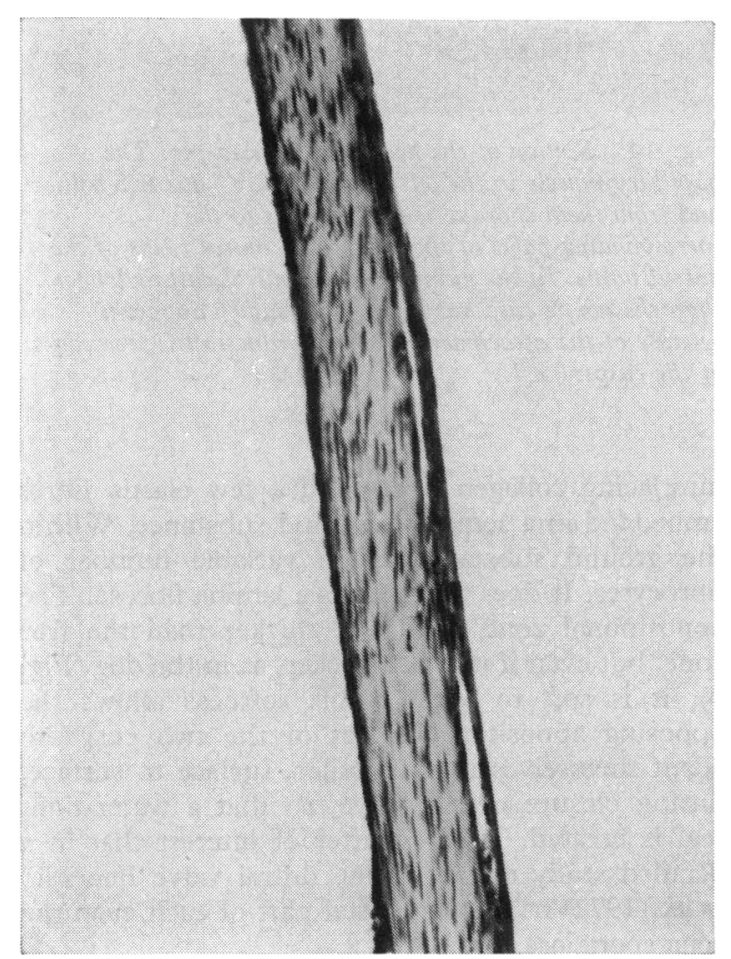

Fig. 15 Part of the free zone of the hedgehog mitral aortic cusp cut longitudinally. The collagen fibres are orientated longitudinally, from the basal attachment to the appositional zone. Flattened fibrocytes lie between collagen fibres. $(\times 180)$.

the collagen fibres provides this part of the cusp with great tensile strength between its fibrous basal attachment proximally and the insertion of the chordae tendineae distally.

The free zone of the human mitral aortic (anterior) cusp has a structural form that is essentially similar to the same zone of the same cusp in the hedgehog (Fig. 15). Though the free zones of cusps with such a collagen pattern have great tensile strength they are likewise endowed with a flexibility that will allow them to billow into the left atrium after apposition of the opposing cusp surfaces during valve closure. Such a 'billowing' is coincident with a narrowing of the atrioventricular orifice. The mechanics of the human mitral valve cusps have been discussed by Clark and Butterworth (1971).

The free zone of the mitral aortic cusp of the sheep has a lamina fibrosa that is formed by a flat plate of extremely dense collagen (Fig. 10): it completely lacks the flexibility that is so characteristic of the human aortic cusp and that of most other mammals. On palpation the free zone of the fresh sheep's aortic cusp is firm and rigid and it is difficult to conceive how it would be possible for it to 'billow' into the left atrium after closure of the valve. The mitral aortic cusp of the ox (Fig. 11) likewise has a firm free zone which is not, however, so rigid as that of the sheep: in all sections made of this ox cusp it had a convexity directed towards the left atrium.

Ranganathan et al. (1970) state that on the human mitral aortic cusp there is a distinct ridge about 8 to $10 \mathrm{~mm}$ from its free edge and that this ridge defines the line of cusp closure. They furthermore state that distal to the ridge there is a palpable rough zone: it is this 'rough' zone that has been named the appositional zone in the present work. The relative lengths of the free and appositional zones varies along the breadths of the cusps: in this study an attempt has always been made to section the mitral valve through the greatest length of the mitral aortic cusp. Many sections in different regions of both aortic and mural cusps have, however, been prepared and examined: these have always shown the same basic features of cusp structure as have been described and reproduced in the figures.

It is considered that a sharp line of demarcation between free and appositional zones is the common pattern in the human mitral aortic cusp. On occasions, however, a ridge is absent, but even when this is so it may well be that the line of closure on the aortic cusp will be determined by a ridge on the mural (posterior) cusp (Fig. 4). Barry and Patten (1960) state that each human atrioventricular cusp has a 'holding face' and a 'deformed face'. In the present work the 'holding face' is the free zone and the 'deformed face' is the appositional zone. They do not make any reference to the line of demarcation 
between the two 'faces' nor do they illustrate them.

Irrespective of the constriction of the mitral orifice that occurs during ventricular systole it is of interest to postulate the manner and sequence in which the appositional zones of the opposing cusps meet each other during valve closure. Van der Spuy (1958), in his description of mitral valve closure, states that as there is a progressive rise in left ventricular pressure, there is also a progressive increase in cusp surface to surface contact. It has been the purpose to this work to refute the concept that all parts of either mitral cusp are structurally and functionally alike: there is a part for apposition and there is a free part to withstand cusp elongation. The real question is, when the mitral cusps are 'flung tight together' (Brock, 1952), do the entire appositional zones meet face to face simultaneously or do the free edges of the cusps meet edge to edge and then the appositional zones roll one against the other until the structurally free zones are reached at the line of closure? At one extreme, it may be that as in the single mobile cusped mitral valve of the hedgehog the entire appositional zone of the freely moving aortic cusp is, during valve closure, thrown against the entire appositional zone that represents the mural cusp (Fig. 13). At the other extreme, as in the dog (Fig. 9) where there is no surface indication of the line of demarcation between free and appositional zones, the mechanism of closure may be different: the edges of the cusps may meet during ventricular systole and thereafter the appositional surfaces roll on each other. From all the anatomical observations that have been made it appears fair to suggest that as there are great differences in valve structure in different animais so, too, there are differences in the method of valve closure.

The presence of left atrial muscle fibres in the mitral cusps has been described many times since Reid (1839) observed them in the horse and ox. Fenoglio et al. (1972) have, indeed, made the presence or absence of muscle fibres in the mitral valve cusps of the dog the criterion for dividing the cusps into histological zones. Montiel (1970), in a study of the human mitral valve, claims that atrial myocardium extends into both valve cusps, but his detailed account and figures relate to the aortic cusp only. In the present study left atrial muscle has always been seen to pass into the subendocardium of the basal part of the human mitral aortic cusp and microscopically it can be seen to extend much farther than is apparent in Fig. 5a and 5b. Left atrial myocardium has not, however, been observed to extend beyond the mitral fibrous ring into the human mural mitral cusp. This pattern is reversed in the rabbit (Fig. 7) and the cat in which left atrial muscle is more prominent in the mural than in the aortic cusp. It is in the dog, however, that a greater amount of muscle is present in both mitral cusps than in any other animal examined. Though it is apparently present only in the aortic cusp in Fig. 9 it can also be seen microscopically in the basal half of the mural cusp. This is in complete agreement with the findings of Fenoglio et al. (1972).

It is postulated that the presence of left atrial muscle fibres within the substance of the free zones of the cusps is associated with the earliest stages of the narrowing of the mitral orifice during valve closure; by their contraction the intracuspal muscle fibres may lend support to the free zones of the cusps.

Cooper et al. (1966), in a study of the canine mitral valve, state that its intravalvar musculature appears to be continuous with the atrial and with the ventricular myocardium. In no animal examined in this work has any ventricular muscle been seen to extend into either cusp of the mitral valve.

The scope of this work is limited to a morphological study by an anatomist of the form, structure, and attachments of the two major cusps of the mitral valve in 12 mammals. The mitral fibrous 'ring' is also fully described and discussed. No attempt has been made to discuss the other structures, including the papillary muscles and the chordae tendineae, which are concerned with the mechanism of closure of the mitral valve. This has been done by Tsakiris et al. (1973) and others.

\section{Conclusions}

The basic pattern of each major mitral cusp is that it has two zones: an appositional zone that comes into contact with a corresponding zone on the opposing cusp during valve closure and a free basal non-appositional zone. The structure of each zone is an expression of its function.

The appositional zone is usually formed, within the endocardium, of a loose meshwork of interlacing collagen fibres embedded in a semifluid ground substance: on palpation it feels soft in the fresh heart. It does not have a lamina fibrosa.

The free non-appositional zone is characterised by the presence of a stratum of collagen fibres, the lamina fibrosa. The character of the lamina fibrosa varies considerably in different mammals. In the human heart the arrangement of the collagen fibres in the aortic cusp in addition to providing great tensile strength also endows it with a flexibility that allows it to billow into the left atrium during valve closure. In the sheep the lamina fibrosa of the aortic cusp is a dense plate of collagen that is firm and nonflexible on palpation in the fresh heart.

A ridge, indicating the line of demarcation be- 
tween the two zones, is usually present on the two cusps in the human mitral valve: when present the ridges represent the 'line of closure' of the valve. This ridge is a prominent feature on the mitral aortic cusps of the ox and the sheep.

The cusps show considerable variation in their relative lengths in different animals. In the heart of the hedgehog there is no mobile mural cusp. In the guinea-pig the mural cusp is longer than the aortic cusp.

The amount of muscle in the two major mitral cusps varies considerably in different animals. The most muscular cusps are those of the dog. The muscle in cusps, when present, is invariably that of the left atrium.

The fibrous mitral 'ring' in the human heart is usually incomplete anteriorly along the entire breadth of the basal attachment of the mitral aortic cusp. This part of the ring has also been found to be absent in the hearts of all other mammals examined. Between the base of the mitral aortic cusp and the basal attachments of the left coronary and noncoronary cusps of the aortic valve there is in man and some other mammals a septum of collagen. This is called the intervalvar septum. In the ruminant ungulates (sheep and ox), there is no intervalvar septum, so that the mitral aortic cusp and the associated cusps of the aortic valve are attached to a common aortico-mitral ring.

The posterior part of the ring is interposed between the myocardium of the left atrium and left ventricle and this corresponds to the attachment of the mitral mural cusp. In man and many mammals this part of the ring is a definite band of collagen: in some mammals, as in the sheep, there is only a thin lamina of loose collagen separating the two chambers of the left heart. It is the relation of the posterior part of the ring to the ventricular myocardium that is responsible for the major changes in the circumference of the ring which occur posteriorly during the cardiac cycle.

The form, structure, and attachments of the two major cusps of the mitral valve indicate that there are considerable basic differences in the mitral valve in different mammals.

The author thanks the Carnegie Trust for the Universities of Scotland for the generous grant for the reproduction in colour of Figure ro. He also thanks Dr Hamish Watson for his help. The highly specialised technical skill required in a work of this nature is considerable and for this the author thanks Mr R. J. Stuart and Mr S. H. Fairhurst. The facilities of the Anatomy Department have been made available to the author through the kindness of the Departmental Head, Professor D. Brynmor Thomas.

\section{References}

Barry, A., and Patten, B. M. (1960). The structure of the adult heart. In Pathology of the Heart, 2nd ed., p. 122. Ed. by S. E. Gould. Charles C. Thomas, Springfield, Illinois.

Brock, R. C. (1952). The surgical and pathological anatomy of the mitral valve. British Heart fournal, 14, 489-513.

Chiechi, M. A., Lees, W. M., and Thompson, R. (1956). Functional anatomy of the normal mitral valve. Fournal of Thoracic Surgery, 32, 378-398.

Clark, R. E., and Butterworth, G. A. M. (1971). Characterization of the mechanics of human aortic and mitral valve leaflets. Surgical Forum, 22, 134-135.

Cooper, T., Napolitano, L. M., Fitzgerald, M. J. T., Moore, K. E., Daggett, W. M., Willman, V. L., Sonnenblick, E. H., and Hanlon, C. R. (1966). Structural basis of cardiac valvar function. Archives of Surgery, 93, 767-771.

Creutzfeldt, O. (1897). Das Flächenwachsthum der menschlichen Atrioventricularklappen. G. Neuenhahn, Jena.

Du Plessis, L. A., and Marchand, P. (1964). The anatomy of the mitral valve and its associated structures. Thorax, 19, 221-227.

Ellison, J. P., and Hibbs, R. G. (1973). The atrioventricular valves of the guinea-pig. 1. A light microscope study. American fournal of Anatomy, 138, 331-346.

Fenoglio, J. J., Pham, T. D., Wit, A. L., Bassett, A. L., and Wagner, B. M. (1972). Canine mitral complex: ultrastructure and electromechanical properties. Circulation Research, 31, 417-430.

Frater, R. W. M., and Ellis, F. H. (1961). The anatomy of the canine mitral valve. Fournal of Surgical Research, 1, 171-178.

Loop, F. D. (1975). Technique for repair and replacement of the mitral valve. Surgical Clinics of North America, 55, 11931204.

Montiel, M. M. (1970). Muscular apparatus of the mitral valve in man and its involvement in left-sided cardiac hypertrophy. American fournal of Cardiology, 26, 341-344.

Ranganathan, N., Lam, J. H. C., Wigle, E. D., and Silver, M. D. (1970). Morphology of the human mitral valve: II. The valve leaflets. Circulation, 41, 459-467.

Reid, J. (1839). Heart. In The Cyclopaedia of Anatomy and Physiology, Vol. 2, p. 589. Ed. by R. B. Todd. Longman, Brown, Green, Longmans, and Roberts, London.

Sahn, D. J., Allen, H. D., Goldberg, S. J., Solinger, R., and Meyer, R. A. (1975). Pediatric echocardiography: a review of its clinical utility. Fournal of Pediatrics, 87, 335-352.

Silverman, M. E., and Hurst, J. W. (1968). The mitral complex. American Heart fournal, 76, 399-418.

Tsakiris, A. G., Sturm, R. E., and Wood, E. H. (1973). Experimental studies on the mechanisms of closure of cardiac valves with use of roentgen video-densitometry. American Fournal of Cardiology, 32, 136-143.

Van der Spuy, J. C. (1958). The functional and clinical anatomy of the mitral valve. British Heart fournal, 20, 471478.

Walmsley, R. (1958). The orientation of the heart and the appearance of its chambers in the adult cadaver. British Heart Fournal, 20, 441-458.

Walmsley, R., and Watson, H. (1966). The outflow tract of the left ventricle. British Heart fournal, 28, 435-447.

Walmsley, R., and Watson, H. (1978). Clinical Anatomy of the Heart. Churchill Livingstone, Edinburgh. In the press.

Walmsley, T. (1929). Quain's Elements of Anatomy, 11 ed. Vol. 4, Part 3: The Heart, p. 47. Longmans, Green, London.

Requests for reprints to Professor R. Walmsley, Department of Anatomy, Bute Medical Buildings, The University, St Andrews KY16 9TS, Scotland. 